\title{
Encontros Entre Cinema e Educação: Imagens de uma Estética do Silício numa Educação de Adultos
}

\section{Cinema and Education Meetings: Images of a Silicon Aesthetics in an Adult's Education}

\begin{abstract}
Resumo: "Quando as forças do homem se compõem com a força do silício, o que acontece, quais novas formas estão em vias de nascer?" Movida pela questão de Deleuze, esta cartografia cria-se no cruzamento de dois temas de interesse: o silício como elemento tomado no filo maquínico do mundo contemporâneo e o cinema como modo de expressão proliferante que se instala nos limiares entre regimes linguísticos e não-linguísticos. Na esteira de Guattari, indaga-se sobre como tornar alguns meios cinematográficos operativos de processos de singularização no âmbito educacional. Neste trajeto, cria-se uma experimentação com um coletivo de professores e alunos do Centro Municipal de Educação dos Trabalhadores - CMET Paulo Freire, da Rede Municipal de Ensino de Porto Alegre/RS, cujo foco centra-se na apropriação de alguns dispositivos cinematográficos pelos educadores e alunos. Busca-se apreender como se atualiza uma estética do silício em modos de aprender com imagem digital, a partir de algumas tecnologias audiovisuais. Palavras-chave: Silício. Cinema. Educação. Agenciamento. Devir.
\end{abstract}

\begin{abstract}
When the human strength composes with silicon's strength, what happens, which new forms can be born?" Moved by Deleuze's question, this cartography is created in the crossroad of two subjects of interest: the silicon as element taken in the machinic phylum of the contemporary world and the audiovisual as a contemporary way of expression that lives in the indiscernible limits between the resonant thing and the appearance. According to Guattari, we ask how to make some audiovisual medias intercessors of singularities processes. In this experimental, nomadic course, we cut out and select a group of teachers and students of the Workers Municipal Educational Centre, called CMET Paulo Freire, to try the appropriation of some audiovisual technologies by educators and students. We look to analyse how these experimental images express silicon aesthetics and how to give power, in teaching practice, new ways of learning with digital image, from some audiovisual technologies.
\end{abstract}

Key-words: Silicon. Cinema. Education. Arrangement. Becoming.

CORRÊA, Elenice Mattos; FONSECA, Tania Mara Galli. Encontros Entre Cinema e Educação: imagens de uma estética do silício numa educação de adultos. Informática na Educação: teoria e prática, Porto Alegre, v. 17, n. 2, p. 149-165, jul./dez. 2014.

\section{Elenice Mattos Corrêa}

\author{
Tania Mara Galli Fonseca \\ Universidade Federal do Rio Grande do Sul
}

0 conceito estética do silício, apresentado neste artigo, visa sublinhar as significativas mudanças nas relações Homem- Natureza na idade da informatização planetária, como a denomina Felix Guattari (1992). O conceito, como um todo fragmentário em permanente devir, é uma multiplicidade conceitual que se compõe por vizinhanças, pontes, cortes, sobreposições ou bifurcações com outros conceitos (DELEUZE; GUATTARI, 1996). Por isso, é ocupado por traços diversos, heterogêneos, intensivos e extensivos, inseparáveis e indiscerníveis, traçando o plano de imanência do conceito.

Estética tem a ver com a vida, pensar uma estética é pensar também uma ética, pois uma é inseparável da outra. Uma ética se define 
por um conjunto de regras facultativas com as quais avaliamos nossa vida prática. Tais regras, só existem em função do modo de existência que elas implicam. Por isso, tais regras são, ao mesmo tempo, éticas e estéticas, por que, por elas, criamos, inventamos novos estilos de vida, produzindo nossa existência como obra de arte (DELEUZE, 2000). Portanto, uma estética do silício reporta-se a um modo de existência que se engendra com a força do silício (Si), ganhando consistência no contemporâneo, na medida em que atravessa inúmeros e diferentes territórios existenciais, econômicos, políticos, tecnológicos, artísticos, culturais, etc., dentre eles, a EDUCAÇÃo.

O homem do século XIX enfrenta a vida, e se compõe com ela como força do carbono. Mas quando as forças do homem se compõem com a [força] do silício, o que acontece, e quais novas formas estão em vias de nascer? (DELEUZE, 2000, p. 125).

Quando Deleuze (2000) nos apresenta tal questionamento, marca a mudança nos agenciamentos Homem-Natureza e o nascimento de uma outra ética-estética. Trata-se de lançar-se à radicalidade da matéria e à literalidade do mundo e pensar o silício como corpo-força de uma ética-estética própria (ZOURABICHVILI, 2005). Deleuze e Guattari (1995) nos instigam a pensar a importância das LIGAS ou ALIANÇAS (composições) que dão consistência a uma sociedade.

Na metalurgia, uma liga é uma mistura homogênea que se dá pela fusão de diferentes metais. Uma liga viabiliza a interpenetração de corpos heterogêneos, em função das conveniências entre os mesmos. Estas conveniências, para bons ou maus encontros, concorrem para que novos modos de existência proliferem. $\mathrm{O}$ encontro se dá quando uma junção de corpos tem potência de dar vida a novos corpos. São por estas ligas, encontros, com suas simpatias, suas conveniências, que cada sociedade seleciona e assimila os elementos técnicos que têm as condições de impulsionar sua existência nos mais variados domínios.

Carbono, ferro, cobre, silício são elementos químicos que compõem o mundo. Bronze, latão, aço, etc. são ligas metálicas com as quais o homem compõe agenciamentos que integram o estrato antropomórfico da Terra (DELEUZE; GUATTARI, 1997b). Assim, o homem, de tempos em tempos, elege, seleciona, toma em seu phylum um conjunto de elementos (carbono, ferro, cobre, silício) para criar suas tecnologias, utensílios (HENGELS, 1976). Estes corpos-forças são tomados pelo homem para com eles entrar em devir, reinventando continuamente a vida, e criando, com isso, seus mundos: feudal, moderno, contemporâneo. Portanto, Idade da Pedra, do Fogo, do Bronze, do Ferro, do Silício, são denominações das marcas históricas tributárias da importância destas matérias-forças e sua utilidade no devir humano.

No mundo contemporâneo, dá-se ênfase às forças do silício, traçando o plano de consistência do mundo. Contemporâneo, muito mais que designar a atualidade e fixar um tempo histórico, implica pensar a complexidade do mundo nos agenciamentos Homem-Natureza. Um agenciamento é uma rede complexa de relações de forças entre corpos heterogêneos que se conectam por vizinhanças, simpatias, simbioses, interpenetrações (DELEUZE; GUATTARI, 1997b). Como um dispositivo, é uma unidade real mínima com a qual produzimos nossos enunciados (DELEUZE; PARNET, 1998).

Assim, a cartografia em pauta, se faz no recorte e análise de alguns agenciamentos selecionados e construídos para expressão de 
uma imagem do pensamento. Esta cartografia, como dimensão teórico-metodológica de pesquisa, sustentada em Deleuze e Guattari, se faz no acompanhamento e na construção de um agenciamento, composto por tantos outros. Este mapa é aberto aos caminhos e movimentos imprevisíveis desta pesquisa-experimentação. Uma pesquisa é uma experimentação que se constuitui a partir dos acontecimentos que afetam o pesquisador. Nesse trajeto experimental e rizomático, produzem-se reenquadramentos, cortes-conexões que são operações do pensamento. Acompanhar rizomas e suas linhas, uma cartografia é isto, uma carta, um mapa, que é nômade, ambulante, imprevisível, desmontável, aberto e passível de constantes modificações. Fazer pesquisa é talhar corpos, criar, montar uma rede heterogênea de relações (agenciamento), construir uma cartografia geofilosófica-científica-artística, aberta, modificável e irreprodutível. Cartografar a marcha da experimentação é fazer rizoma com o que se passa, enquanto a experimentação anda.

Andar e pensar um pouco, que só sei pensar andando. Três passos, e minhas pernas já estão pensando, Aonde vão dar estes passos? Acima, abaixo? Além?

Ou acaso se desfazem ao mínimo vento sem deixar nenhum traço? (LEMINSKI, 1994, p.39)

O elemento químico $\mathrm{Si}$, na tabela periódica, encontra-se na classificação dos semi-metais. Esta matéria corresponde a $25 \%$ do peso da crosta terrestre e participa da constituição de uma infinidade de corpos orgânicos e não-orgânicos. Isso faz com que ele funcione como um quantum de tranversalidade. Como compo- nente da terra, é nômade, é um corpo simples que atravessa diferentes corpos e expressa as linhas de desterritorialização da Terra desterritorializada. As linhas de desterritorialização, indissociáveis das linhas de reterritorialização, são componentes de um agenciamento, já que o recorte nunca é estático, mas uma matéria em movimento (DELEUZE; GUATTARI, 1997b). A reterritorialização designa as linhas de integração que estratificam o agenciamento num território. Simultâneamente, a desterritorialização opera linhas de fuga que abalam e esgarçam o território. Estas podem ser compensadas por novas linhas de integração acompanhadas por novas fugas que abrem o agenciamento territorial aos intercessores que o reinventam continuamente. Neste sentido, um agenciamento vive em permanentes transmutações visto que sua reinvenção tende ao infinito.

Assim, o silício, alastra-se como uma fibra que vai do homem, ao animal, ao mineral, às células, às moléculas, etc., por uma linha de desterritorialização que é a condição de aliança necessária ao devir, vive de sua desterritorialização e reterritorialização permanente (DELEUZE; GUATTARI, 1997a). A simbiose homem-silício traça um devir. Neste agenciamento, torna-se linha de desterritorialização na composição das máquinas sociais e técnicas contemporâneas e força propulsora de novos modos de sentir, pensar e agir.

Hoje, assiste-se a alguma coisa muito curiosa: a revanche do silício. Os biologistas que demandaram frequentemente porque a vida era passada pelo carbono, mais do que pelo silício. Mas a vida das máquinas modernas passa pelo silício: é toda uma vida não orgânica, distinta da vida orgânica do carbono. Falar-se-á, neste sentido, de um agenciamento silício. (DELEUZE, 2003, p. 164-165) 
Portanto, o silício é corpo expressivo e, por isso, estético. Nos agenciamentos-obras em que se engendra, encontramos uma estética. Tomado nos agenciamentos tecnológicos contemporâneos, participa da ênfase tecnológica do mundo, a microeletrônica, tornando-se matéria expressiva deste estado de coisas. 0 circuito integrado, como dispositivo da microeletrônica, imprescinde de um substrato de material semicondutor. A função semicontudora do silício, potencializada pelo agencimento com outros elementos, permite a produção de transistores, chips, em uma variedade de circuitos eletrônicos. Um semicondutor é assim designado por possuir uma condutividade elétrica intermediária entre um condutor e um isolador, com o qual pode-se transmitir e controlar uma corrente elétrica (ENDERLEIN, 1994). O agenciamento silício-microeletrônica cria o chip, um arranjo entre a fotolitografia que possibilita a miniaturização do circuito eletrônico; o código numérico que acompanha a miniaturização com a compactação da informação; a telecomunicação que expande a comunicação à distância em velocidade de conexão instantânea. Com ele, acelera-se a miniaturização dos corpos e a velocidade de transmissão de dados. Em que pese as pesquisas sobre semicondutores prevejam a superação do silício por outros componentes, como o grafeno (de base carbônica), ainda hoje, é com silício que se sustentam as atuais e significativas mutações tecnológicas, econômicas, políticas, éticas e estéticas.

A microeletrônica, com seus aparelhos (código numérico, circuito integrado, TIs, computador, internet, programas para os mais variados fins, etc.), com seus modos de agregação social (emails, comunidades virtuais, redes sociais, blogs, orkut, facebook, youtube, etc.), com suas economias (capitalismo mundial in- tegrado - CMI), com suas políticas, com seus modos de apropriacão na educação, etc., é produto-produtora de uma ética-estética e é engendrada por ela. Como máquina técnico-científica das TIs, dissemina um modo de vida produto-produtor das renovações de um capitalismo hegemônico, que se sustenta na velocidade e no controle da circulação do capital e da informação. Tais tecnologias nascem reterritorializadas e para reterritorializar nesta trama capitalística. Seu uso hegemônico, orientado à produção capitalística do mundo, é uma das importantes implicações de uma estética do silício nessa era. As forças do homem tomam as forças do silício em seu phylum para dar nascimento as TIs e com elas operar a proliferação e diversificação dos meios de reterritorialização nos processos de subjetivação dominantes, visando o consumo, o lucro, as grandes concentrações de capital e suas relações de poder.

Os agenciamentos maquínicos das TIs enganchados à educação, fortalecem as funções diagramáticas que atravessam as sociedades de controle. As TIs consolidam uma ética-estética regida hegemônicamente pelo Capitalismo Mundial Integrado - CMI. A educação, por sua vez, é peça da máquina abstrata de visageidade do mundo. Esta máquina abstrata dominante, consolida a imagem padrão majoritária do homem (Homem - Branco - Urbano - Letrado - Saudável - Equipado de cinco sentidos funcionais - Financeiramente estabilizado) que domina e que esmaga sutil ou explicitamente as singularidades em devir. Por isso, a Máquina-Educação, da qual faz parte o $\mathrm{CMET}^{1}$, é predominantemente conservadora.

A função diagramática educar toma as máquinas técnicas de um modo de produção cine-

\footnotetext{
Centro Municipal de Educação dos Trabalhadores - CMET Paulo Freire. Rede Municipal de Ensino (RME) de Porto Alegre/ RS.
} 
matográfico disseminado pelas TIs, para fazer um cinema que educa, ou de outro modo, uma educação que age através de um cinema. Juntas, alicerçam uma gigantesca máquina de estratificação. Na esfera das políticas públicas da educação formal brasileira os encontros com o cinema reportam-se aos anos 1920, período da reforma educacional. Sob uma imagem progressista de ensino, utilizava-se o cinema como recurso auxiliar para uma educação moderna. Subordinado às orientações da máquina de Estado, o cinema sujeita-se ao educar e instruir. Em outro vetor, é o cinema que atravessa o domínio educativo, construindo imagens da educação. Ao tomar a educação como elemento da ação narrativa, muitos filmes corroboram com uma imagem-clichê condicionante da escola, do professor, do aluno e das funções educar, ensinar, aprender, sob o poder do modelo.

Simultaneamente, abrem-se linhas de desterritorialização que, através da proliferação e da diversificação das formas expressivas, dão ênfase a modos de expressão artísticos inusitados e disseminados na população. A estética do silício facilita e dissemina o cinema digital como modo de expressão produtor de um bloco de sensações indiscernível do material que o constitui (píxel, código numérico, microeletrônica, chip, silício, etc.). As TIs permitem a proliferação de matérias cinematográficas expressivas que circulam em suas redes ${ }^{2}$. Artistas como VJ Luiz Duva, Pogo, por exemplo, apropriam-se de algumas tecnologias do vídeo digital para operarem no limiar de uma forma que não consegue ser capturada por um formato audiovisual pré-concebido, sem que se lance em traços de outros formatos, misturas

\footnotetext{
2 Colocamos em destaque as formas audiovisuais eletrônicas que proliferam hoje: via rede, via Youtube, via televisão, via celulares, tocadores de áudio e vídeo, etc. Dentre elas, os Parangolés Eletrônicos, experimentações audiovisuais contemporâneas que nascem na conjugação da atividade do $\mathrm{Dj}$ e do Vj (CORRÊA, 2008).
}

onde a imagem visual adquire comportamentos sonoros e vice-versa ${ }^{3}$. Assim, por linhas de reterritorialização e desterritorialização, a funÇÃo ESTÉTICA do silício, como um suplemento do estrato antropomórfico, serve tanto aos procedimentos das sociedades de controle e de consumo, quanto aos movimentos de resistência a elas.

Na educação, reside um hiato entre um modelo de ensino que ainda perdura em práticas educativas que pouco incorporam as TIs neste fazer cotidiano. Com a velocidade acelerada dos avanços tecnológicos, mantêm-se ou amplia-se o hiato existente. Neste sentido, este hiato ou, por vezes, abismo entre este universo tecnológico informacional e um modelo escolar ainda moderno de ensino-aprendiazagem, é uma das repercussões de uma estética do silício no âmbito educacional.

É, portanto, neste cruzamento de forças entre o silício, importante componente das TIs, o cinema, modo de expressão que ao acoplar-se à tais tecnologias se dissemina e prolifera como força expressiva de singularidades emergentes, e a educação, máquina a serviço de uma visageidade dominante, que se cria esta cartografia. O interesse em pensar as forças que fabricam o contemporâneo une-se a atração pela matéria cinematográfica como dispositivo do pensamento. $O$ desejo que nos move é o de romper com a clássica hegemonia da função escolar, investindo numa linha de resistência por um fazer cinema que possa abrir o agenciamento educacional a outras forças. Entedemos cinema como modo de expressão e não como linguagem na medida em que suplanta-se a categorização linguística entre cinema e vídeo. Assim, ingressamos num pequeno fragmento do CMET Paulo Freire para

\footnotetext{
3 Disponível em: <www.liveimages.com.br; www.youtube com/watch?v=A2yt1ooLQGo>
} 
cartografar a imersão nesta experimentação e analisar a insersão de algumas TIs na educação, operando como máquina de produção de aprendizagem e de subjetivação e como arma de produção de processos criativos e de singularização.

A entrada no CMET, como pesquisadora, se deu através de uma proposta de oficina para os professores interessados, cujo objetivo era introduzir os recursos audiovisuais da filmadora digital, do programa MovieMaker de edição de vídeo e do computador, com o intuito de experimentar modos de exploração dos mesmos na atividade pedagógica destes professores com seus alunos. Para tanto, fez-se necessária uma imersão primeira, a fim de mapear os modos de inserção e apropriação do computador e seus recursos dentro do CMET.

Neste mergulho no CMET, surgem outras indagações pertinentes à experimentação em marcha: como funciona a máquina CMET? Como incorpora nesta educação de adultos algumas TIs? E, como componente deste funcionamento maquínico, como este professor incorpora tais tecnologias em seu fazer docente? São questões que movem o mapeamento da máquina CMET para iniciar-se uma experimentação. Esta rede complexa CMET constitui um agenciamento de conteúdos e de expressões (DELEUZE; PARNET, 1998). Em uma face, o agenciamento CMET mostra-nos uma mistura heterogênea de corpos em um recorte de uma realidade. Simultaneamente, há uma outra face, da expressão, onde o agenciamento CMET encarna os acontecimentos que o modificam ininterruptamente. Os acontecimentos, são os incorporais, expressos em verbos infinitivos (educar, ensinar, aprender, pesquisar, fazer cinema ou cinear, etc.), que subsistem num agencimento de corpos e que neles se atualizam.
O CMET compreende um coletivo em torno de 1.000 alunos entre os 15 e os 90 anos, uma diversidade de adultos e jovens trabalhadores, sendo uma parcela composta por alunos denominados deficientes (cegos, surdos, síndrome de down, autismo, etc.), alguns com graves déficits de aprendizagem, outros em vulnerabilidade social, que repercute nas peculiaridades de maquinarias da instituição. O CMET dispõe de uma Sala de Integração e Recursos voltada para os cegos - SIR $^{4}$ visual, com a atividade de professores especializados na aquisição da linguagem Braile e na utilização de programas específicos como o DosVox; possui turmas específicas para os surdos, contando com o trabalho de um professor especializado no aprimoramento da língua brasileira de sinais Libras; e, também, apoio pedagógico pelo professor de educação especial aos demais alunos com certas deficiências ${ }^{5}$. Assim, torna-se traço de uma estética do silício nesta instituição de ensino, esta apropriação tecnológica orientada à linguagem. Há no CMET uma maquinaria montada para o aprendizado e aprimoramento de línguas: português e idiomas estrangeiros, Braile e Libras.

Como membro da equipe docente do CMET no período de 2004 a 2009 e como pesquisadora no período de 2010 a 2012, foi possível acompanhar e participar, de alguns dos movimentos de apropriação de algumas TIs nesta instituição. Durante este período o CMET possuía e possui um conjunto de computadores distribuídos em, praticamente, todos os espaços administrativos e pedagógicos da escola, dos quais, destaca-se o laboratório de informática.

\footnotetext{
${ }^{4}$ As SIRs são um serviço de apoio aos alunos com necessidades educativas especiais no ensino fundamental. Disponível em: $<>$

${ }^{5}$ Cabe ressaltar que a denominação deficiência reporta-se ao modelo majoritário de homem que se impõem como visageidade dominante.
} 
Seguindo a política pedagógica da Rede Municipal de Ensino (RME), os laboratórios de informática escolares funcionam (em tese) com a presença de um estagiário em cada turno, cuja função é auxiliar os professores e alunos nas atividades que desenvolvem neste espaço. Durante os horários de aula, este laboratório costumava estar frequentemente ocupado. As duas principais funções dos computadores eram a pesquisa ou navegação pela internet (pesquisar, navegar) e a digitação de textos (digitar). Em função da grande demanda, a ocupação do laboratório organizava-se por uma planilha de distribuição de horários entre turmas e professores, acarretando, na prática, um contato esporádico dos alunos com este espaço. O laboratório de informática e os setores da escola eram, e continuam sendo, os dois modos institucionalizados da informática na educação nesta instituição.

Neste período de pesquisa, cada sala de aula contava com um computador dos mais antigos, provenientes de uma renovação dos equipamentos do laboratório de informática. A entrada deste computador com acesso à internet, provocou, na época, uma tímida mutação na dinâmica de aula de alguns professores. Apesar que muitos deles já utilizassem o computador na sua vida particular, ainda assim era difícil pensar este equipamento na prática pedagógica. Quando usados pelos alunos, sua principal função era a conexão com a internet para acesso a emails, facebook ou para a pesquisa e a digitação de textos. Era comum os professores darem suas aulas ao lado destes computadores, geralmente instalados em um canto próximo à mesa do professor, para que, de certa maneira, não atrapalhassem a aula. Esta tímida e possível ocupação destas máquinas deve-se, em parte, a fatores técnicos como: a baixa velocidade dos computadores antigos, as avarias de funcionamento e as dificuldades de manuntenção. O que ocorria no CMET é que depositava-se um computador em cada sala de aula sem se pensar muito bem para o que. Outro fator importante era a dificuldade na utilização destes recursos por alguns professores pelo desconhecimento e receio em mexer com estas máquinas. Uma parte deste coletivo fazia um uso bastante restrito na sua vida. Este modo subjetivado de relação expressa no distânciamento e suspeita com os computadores e seus recursos, se coloca como traço desta ética-estética nesta instituição de ensino. Trata-se de um gargalo, um ponto de estrangulamento das TIs no CMET e, possivelmente, na educação.

Ficam visíveis algumas relações de poder entre os espaços administrativos e pedagógicos, mostrando como uma estética do silício atualiza-se nesta instituição educacional (ou em várias). Os computadores mais novos e de melhor funcionamento encontram-se em algumas salas administrativas, no laboratório de informática, na biblioteca, enquanto que os mais antigos e sucateados foram encaminhados para o espaço da vida cotidiana escolar, a sala de aula. A distribuição das máquinas técnicas no corpo CMET, priorizando os espaços de gestão administrativa e de certa instância pedagógica (a do laboratório de informática) parece atender a ênfase autoconservadora da instituição dentro de um agenciamento educacional RME, que faz parte de um agenciamento Educação Nacional.

O projeto de informatização das escolas de RME, com relação aos modos de distribuição e de ocupação das TIs, enfrenta uma espécie de estagnação neste modelo de funcionamento. No CMET e, em geral, nas demais escolas de RME, encontramo-nos diante de um esgotamento da concepção que aprisiona a infor- 
mática em um laboratório. Era recorrente no discurso dos professores e alunos que o uso esporádico do laboratório não propiciava a nenhum deles uma experimentação efetiva e qualitativa das TIs na prática docente/discente. A disposição arquitetônica dos computadores em um espaço escolar como este expressa o quanto as TIs ocupam ainda um lugar à margem do cotidiano da sala de aula. Que ética-estética e que imagem da informática se cria com a fixação desta atividade ao modelo laboratório? O importante, aqui, é colocar a questão mais do que respondê-la. A institucionalização e aprisionamento da informática na educação em laboratórios destaca-se como força reterritorializante de uma estética do silício nesta instituição de ensino. Este é um sinal de como, efetivamente, ela se consolida no território existencial da educação, conservando uma distância entre a esfera da prática docente em sala de aula e a informática. O laboratório de informática guarda a informática educativa: é lá que ela vai residir.

A inclusão digital, termo largamente utilizado para referir-se a projetos de acessibilidade às TIs para uma parcela de sociedade que vive à margem delas, se faz nesta lógica que mantém a atividade informática fora da sala de aula. Reforça-se o binômio inclusão-exclusão que alimenta o phylum capitalístico das sociedades de controle, pois incluídos no funcionamento maquínico de uma máquina mundial disciplinadora da educação, todos aí estamos, inclusive, os assim chamados excluídos. Faz parte desta lógica preservar este binômio como bem distintivo de uma mais valia econômico-político-cultural-social, alavancando distintas fatias de mercado-consumidor.

Além das máquinas fixas, o CMET possui também as ambulantes - máquinas fotográficas e filmadoras digitais e notebooks com pro- gramas de edição em vídeo - das quais nos apropriamos para a experimentação com o intuito de levá-las, efetivamente, para o espaço educativo da sala de aula. Ressaltamos a necessidade de incorporar tais TIs na arquitetura e na dinâmica da sala de aula, para que, de fato, se possibilite uma apropriação qualitativa das mesmas. Operamos na direção da dissolução gradativa dos laboratórios de informática em favor da sala de aula em seu cotidiano vivo. Por isso, investimos na mobilidade dos notebooks, visando uma estética capaz de suscitar novas formas maquínicas e singularizantes.

Desta forma, ingressamos na análise de algumas das experimentações com a filmagem e com a montagem em vídeo digital, realizadas por algumas professoras durante ou posteriormente à oficina, para analisar as expressões de uma estética do silício nestes agenciamentos imagéticos. É preciso ir em busca de novas pastagens e achar um meio capaz de difundir ideias novas, pois as ideias novas estão no domínio da liberdade. Nessa linha de fuga instalam-se as questões que embalam a experimentação. Como tornar um cinema digital um meio operativo, potente e intercessor de processos de singularização no âmbito educacional? $\mathrm{O}$ que pode este conjunto de mídias numa prática docente cujo evento cinema está em composição com o evento aprender? Como a experimentação com um fazer cinema afeta professoras, pesquisadora e alunos? A importância de criar-se um problema não está em respondê-lo, mas em suscitar as inquietações que fazem mover a pesquisa.

A experimentação foi disparada a partir da proposta da oficina apresentada ao coletivo de professores do centro em uma reunião pedagógica no início do ano de 2010. A partir daí formou-se um grupo de 6 professoras que se interessaram pelo projeto, bem como o coleti- 
vo maior, em torno de 20 professores, que participaram de uma discusão teórica a cerca dos conceitos de imagem e cinema. Esta primeira fase da pesquisa ocorreu ao longo dos meses de maio à dezembro do referido ano, num total de oito encontros coletivos, geralmente quinzenais, e muitos individuais, concentrados nos meses de novembro e dezembro, com as 2 professoras que levaram adiante projetos de montagem.

Como já mencioinado, a proposta da oficina era introduzir e experimentar as câmeras fotográfica e filmadora digital, os notebooks da escola e o programa MovieMaker para edição de vídeos, com o intuito de proliferar o uso e abrir novas possibilidades disseminadas por este conjunto de TIs. Este coletivo de professoras, pouca ou nenhuma relação tinham com estes recursos. De modo geral, algumas delas limitavam-se ao acesso esporádico a email e internet. Essa realidade fez com que o grupo passasse por uma aprendizagem de alguns procedimentos básicos de operação do computador como: a utilização de um pendrive, a criação de pastas, a transferência de arquivos, etc. Assim, a oficina, ou seja, um conjunto imprevisível de encontros, vivia de sua reinvenção permantente, pois se recriava a cada encontro realizado. Com isso, esse processo oscilava na tensão entre vontade e imobilidade, o receio diante destas máquinas computacionais e o aumento de potência pela conquista de uma operação até então desconhecida. E, este aumento de potência, é a linha de fuga ao modo subjetivado de relação com tais tecnologias, tornando-se força desta ética-estética e desta pesquisa-experimentação.

Afetar e ser afetado por uma estética do silício são eventos ou acontecimentos encarnados pela oficina. Visa-se afetar os corpos através de uma experimentação com cinema em vídeo digital. Pretende-se chamar a atenção aos modos de expressão visuais e sonoros cinematográficos para dar ênfase a alguns regimes de signos não-ligúísticos a fim de problematizar a ocupação hegemônica das TIs voltada a apropriação de línguas (o português, o Braile ou a LIBRAS), mapeada na primeira imersão no CMET. Trata-se de uma tentativa de potencializar os processos criativos das professoras e dos alunos com o uso de algumas ferramentas cinematográficas para que possam, a seu tempo, investir nestes recursos descobrindo e inventando novas dinâmicas pedagógicas.

Investe-se na matéria cinematográfica também como modo de fazer pesquisa. Deleuze (2005, p. 227) enfatiza que pensar "[...]é apreender o que pode um corpo não-pensante, sua capacidade, suas atitudes[...]" e que o cinema experimental pode dar um corpo para pensar quando monta uma câmera sobre um corpo cotidiano. Sendo corpo tudo aquilo em que o pensamento mergulha para pensar, esse mergulho olha para o que este corpo pode (a experimentação em marcha), a partir das suas capacidades, atitudes, posturas, para forçar um pensamento que vise o impensado a partir do que afecta a câmera. Por câmera, entende-se um aparelho de captura audiovisual, tanto microeletrônico quanto biológico, operando sobre um corpo cotidiano para fazer a experimentação.

Por isso, operamos a câmera microeletrônica acoplada ao olho humano do operador-pesquisador para captar imagens em movimento. A câmera opera uma experimentação, cuja matéria expressiva constitui-se de elementos diversos: gestos, vozes, músicas, palavras, enquadramentos ${ }^{6}$, planos, ângulos, movimen-

\footnotetext{
${ }^{6}$ Enquadramento: de relevante importância para o cinema designa o que fará ou não parte do filme, ou seja, o que a câmera mostrará em quadro e o que ela deixará de fora. Plano: como principal componente do enquadramento, ele define ba-
} 
tos de câmera, píxels, bits, paisagens, ideias, conceitos, funções, blocos de sensações. As imagens que se constróem são inextrincáveis agenciamentos de uma estética onde o silício torna-se matéria expressiva de pesquisa, cujos fluxos molares e moleculares delineiam traços desta ética-estética que se engendra à máquina CMET. São traços audiovisuais que, via luz e som, fazem fulgurar o pensamento. A palavra é uma das forças, tanto visual quanto sonora, contida na imagem em movimento. Trata-se de fazer mergulhar o pensamento e os sentidos nesta matéria movente. O cinema, assim, instala-se nos limiares indiscerníveis entre o sonoro e o visual, entre regimens linguísticos e não-linguísticos, como expressão do pensamento.

Deleuze (2005) instiga o pensamento ao analisar imagens cinematográficas das obras de alguns cineastas importantes para a arte do cinema. São com imagens-tempo e imagens-movimento que se produz tal experimentação. Imagem-tempo e imagem-movimento são dois conceitos estudados por Deleuze, a partir das críticas bergsonianas ao cinema (BERGSON, 2005). O conceito de imagem trata da estreita relação dos sentidos humanos com o mundo. A imagem-movimento está na sucessão dos enquadramentos, trata-se dos vínculos sensórios-motores da imagem, do tempo cronológico da narrativa e de um espaço estriado, fornecendo uma apreensão indireta do tempo. Já a imagem-tempo designa uma apreensão direta do tempo, que independe da montagem

sicamente a distância entre a câmera e o objeto a ser filmado, dividindo-se, em linhas gerais, entre "plano aberto" (distante do objeto, este ocupa pequena parte do enquadramento, com ele apresenta-se o ambiente onde se passa uma determinada cena), "plano médio" (em menor distância do objeto, este agora ocupa uma boa parte do enquadramento) e "plano fechado", mais conhecido por "close-up" (o mais próximo do objeto, este ocupa quase todo o enquadramento, considerado um plano que agrega intimidade e capta as expressões dos personagens) (GERBASE, 2012). sucessiva, pois a composição audiovisual possibilita um folhamento (atual e virtual) no próprio tempo, abrindo-nos ao plano de vidência da atividade do pensar.

Ao extrair, explorar, fabular com pequenas porções da matéria sonora e luminosa do mundo e ser encarnado por elas, fazer cinema ou cinear pode fissurar a dureza do poder, fabricando máquinas de guerra. Tal cinema pode facilitar a busca do devir-filósofo, do devir-artista-cineasta, do devir criança, de cada um dos envolvidos em seus processos fugidios, potencializando processos de singularização que enfraqueçam os modos de subjetivação que barram a efervescência de um novo devir-homem. Neste sentido, engancha-se ao aprender na medida em que este reporta-se a uma abertura aos encontros que possibilitam a tessitura da imanência. Abrem-se pequenas fendas na máquina diagramática educacional CMET, disparadas por este fazer cinema, dando vazão a um processo inventivo de andar em bando e aprender na alegria. O trajeto se faz nômade e rizomático, traçando em um mapa de afetos e perceptos que embaralha pesquisadora, professoras e alunos.

Assim, ingressamos numa coleção de peças audiovisuais experimentais recortadas para esta análise, divididas-se em duas espécies: 1. a experimentação do processo de gravação videográfica com a filmadora ou câmera digital, 2. a experimentação com o processo de montagem fílmica com o programa Movie Maker disponível nos notebooks da escola.

Das experimentações com a câmera, resultaram vários fragmentos videográficos, dos quais selecionamos para o momento a experimentação de um passeio sem cortes, em um único plano-sequência ${ }^{7}$ experimentando o tra-

7 Plano-sequência: designa o intervalo de tempo em que se 
velling ${ }^{8}$ com a câmera e um conjunto de fragmentos fílmicos muito curtos denominados as quase fotografias. Nota-se que, dos conteúdos filmados pelas professoras, tanto no travelling quanto nas quase fotografias, encontram-se corredores, salas de aula ou de trabalhos especializados, banheiros, espelhos, escadas, luminárias, em momento algum o laboratório de informática ou os computadores de sala de aula foram foco de enquadramento, reforçando o lugar que tais tecnologias ocupam nas imagens cinematográfica desta experimentação.

Um plano, um travelling, um tempo, consiste em um único plano-seqüência em travelling de 4 minutos, realizado por uma das professoras que, pela primeira vez, experimentava a filmagem com a câmera e a transferência destes arquivos para o computador. Ela liga a câmera e dialoga enquanto enquadra imagens visuais. Por vezes este diálogo entra em redundância com a imagem visual, descrevendo o que está sendo visto: "fulana" veste o casaco ... agora estamos no banheiro ..., por vezes entra em disjunção quando deixa ver uma outra imagem pelo som que corre paraleo e disjunto ao passeio visual pelos corredores: vamos ver se está filmando ... tem um botãozinho aqui ... será que está gravando? Da redundância à disjunção são transformações qualitativas importantes que ocorrem na imagem. Estes deslizamentos, próprios do cinema do pós-guerra europeu analisado por Deleuze, quando agenciados às TIs, tornam-se traços de uma estética do silício, sublinhando as mutações da imagem cinematográfica e do pensamento. De uma instância em que imagem e

da cena ou ação, do momento em que se liga a câmera até o momento em que se para a filmagem, através de uma única "tomada" (um tempo de filmagem) (GERBASE, 2012).

8 Travelling: designa um tipo de movimento de câmera em que esta desloca-se na mão do operador, acompanhando os movimentos de uma ou mais cenas ou descrevendo um ambiente (GERBASE, 2012). pensamento encontram-se circunscritos nos limites da imagem-movimento (quando enquadra e narra oralmente, em redundância, uma ação), a experimentação desliza para uma imagem em que o encadeamento sensório motor da imagem em movimento é rompido pelo espaçamento entre imagem visual e sonora, dando-nos a ver uma imagem direta do tempo. Rompe-se um modo de apreender-pensar centrado nos encadeamentos sensórios-motores, dando lugar a um tempo da observação, um cinema da vidência que se faz na perambulação. O que se expressa nesta imagem é a própria experimentação da professora como expressão de um tempo.

Nas quase fotografias, a professora utiliza uma máquina fotográfica na função filmadora, operando uma desterritorialização e reterritorialização de uma em outra. É traço de uma estética do silício estas ligas tecnológicas que aglutinam em um mesmo aparato técnico inúmeras funções. A câmera digital a pixel, como ponta de desterritorialização do phylum maquínico que toma o silício, faz o entrecruzamento, a combinação e a desterritorialização das funções de, pelo menos, duas máquinas técnicas: ela fotografa e filma imagens visuais e grava imagens sonoras. Por sua vez, cede lugar ao celular que faz fotos, filmes, acessa a internet, agenda compromissos, desperta, etc. e, também, telefona. As quase fotografias reportam-se a fragmentos fílmicos mínimos em gravações extremamente curtas mostrando uma exploração do tempo. É indiscernível a apreensão da imagem visual sem que seja necessário repetir-se o fragmento inúmeras vezes. O que salta destas imagens é o som do clic da máquina. Esta experimentação leva-nos a indagar qual o tempo de um disparo? Um disparo fotográfico, um disparo do pensamento? 
Das experimentações com a montagem, foi proposto às professoras criarem um modo de apropriação destes recursos em uma atividade ligada à sua prática docente. A partir do desafio, surgiram dois projetos: Olhares Sobre o Mundo, um projeto fílmico para e com os alunos deficientes auditivos criado pela professora de geografia para encerramento de um conteúdo da matéria; $O$ ano está terminando, mas o que vai ficar na lembrança?, um documentário integrante do encerramento do ano letivo da professora regente de uma turma de Totalidade Inicial $3^{9}$. Por último, como produto de culminância da pesquisa, surge, nos anos seguintes à oficina (2011/12), o projeto fílmico Histórias de Susto e Assombração, após a experimentação da professora com o referido documentário.

Olhares Sobre o Mundo trata-se de um filme surdo (CORRÊA; FONSECA; PASSERINO, 2011). O filme surdo refere-se a um projeto fílmico desprovido do som, desenvolvido pela professora de geografia para e com seus alunos deficientes auditivos. Essa montagem é composta de uma gravação em que cada aluno apresenta sua pesquisa a cerca de um país, combinada a fotografias, desenhos, textos, enxertados pela professora, com o objetivo de fazer uma descrição do estudo para apresentar aos alunos. É o processo criativo de um professor que se aventura a experimentar com as TIs, que parte de um roteiro básico que vai

\footnotetext{
9 A organização formal do ensino na educação de adultos na Rede Municipal de Ensido de Porto Alegre é dividida em 6 Totalidades: 3Totalidades Iniciais (TIs) e 3 Totalidades Finais (TFs), que configuram os níveis de ensino da EJA e que correspondem aos 9 anos do ensino fundamental, seguindo o mesmo modelo escolar que divide o ensino em duas grandes etapas: um período inicial na lógica da unidocência, um professor que atravessa diferentes campos de conhecimento (também denominada currículo por atividades), e um período final, que corresponde ao denominado currículo por área, que compreende, no CMET, oito matérias: português, matemática, ciências, artes, educação física, língua estrangeira, história e geografia.
}

compondo com o que encontra na internet. Trata-se de imagem-movimento que apresenta coisas de diferentes países (mapa do país e do continente, capital, moeda, culinária, ênfases culturais, etc.), pelo processo de recognição. Trata-se de uma montagem visual construída no âmbito do material didático. Pelo compromisso com os conteúdos disciplinares, o filme surdo encontra-se reterritorializado na ciência pedagógica, pela forte tendência que temos (professores) em pedagogizar as formas expressivas. Assim, mostra-se uma face de uma estética do silício direcionada à pedagogização dos recursos técnicos, permitindo perceber o modo hegemônico de pensar e inserir as TIs no âmbito da educação com a proliferação de materiais didáticos.

$O$ ano está terminando, mas o que vai ficar na lembrança? Assim começa a montagem fílmica experimental da professora ao produzir uma cartografia audiovisual da trajetória de um ano letivo vivido com sua turma. Uma turma composta por homens e mulheres, idosos e jovens, autistas, deficientes visuais, todos portadores de alguma diferença. Tece uma narrativa audiovisual que percorre as experiências de aprendizagem vividas ao longo do ano: leituras feitas em aula, jogos, passeios, mudanças na sala de aula, etc. A professora indaga-se sobre o que ficou, o que marcou cada aluno e mostra o que se conservou para ela desta experimentação docente. Rememorar histórias ou conteúdos desenvolvidos faz parte deste agenciamento audiovisual para lançar-se a um momento vivido num coletivo e, por ele, ao uma memória do mundo, quando experienciam um aprender nos acontecimentos. A composição mostra uma trajetória de uma vida vivida neste coletivo, professora e alunos, que povoa a cartografia audiovisual com afectos e 
com perceptos ${ }^{10}$, que percorrem o ano letivo, por onde o aprender acontece.

As montagens bricoleurs exploram a colagem como procedimento composicional, intensificada pelas disponibilidades da web e pelo software de montagem audiovisual, compondo com o que se encontra, sobrepondo, justapondo, encadeando imagens. Tratam-se de bricolagens entre gravações de momentos com alunos e outros materiais diversos selecionados de diferentes fontes: internet, Cds, máquina fotográfica, filmadora. A bricolagem de conteúdos e tecnologias, como operação de montagem e do pensamento, repercute modos composicionais do Dadaísmo, da Arte Pop, da Música Eletrônica ou Eletroacústica, que se atualizam e potencializam com as TIs, tornando-se traço de uma estética do silício (CORRÊA, 2008).

Estas experimentações exprimem, cada uma, um processo criativo singular que põe em operação uma potência de cada pensamento. Trata-se das primeiras experimentações de um coletivo de professoras, que buscam encontrar um meio de apropriar-se da matéria audiovisual e algumas TIs e em suas práticas docentes. A potência das obras está na própria experimentação, no processo, no esforço em superar o receio de desbravar a técnica. O artista-criança ao deparar-se com um novo material, uma nova técnica, passa por uma experimentação que, por vezes, retoma modelos

\footnotetext{
${ }_{10}$ Atravessados pelo pensamento de Bergson, Deleuze e Guattari, compreendem os afectos e os perceptos em distinção às percepções ou afecções. Os afectos e os perceptos ultrapassam o vivido humano, justamente por que trata-sedo humano imerso num estado de coisas e num tempo (numa duração) e atravessado por ele. Ao contrário, as afecções e percepções, fixam-se no humano como centro de observação separado do mundo. Por isso, os afectos são devires não humanos do homem e os perceptos são paisagens não humanas da Natureza. A paisagem é anterior ao homem, vive na sua ausência. $A$ paisagem é invisível, por que quanto mais a conquistamos, mais nela nos perdemos. Assim, tudo torna-se visão e a visão é o que do invisível se torna visível. (DELEUZE; GUATTARI, 1996, p. 218-219).
}

vividos. Assim, um professor-artista-criança vive nestas experimentações, um jeito de tornar a matéria expressiva.

Finda-se o ano de 2010 e a impressão de uma força provocada através da oficina opera deslocamentos que fazem a pesquisa ingressar em uma segunda fase, em 2011/12, prolongando-se na criação das Histórias de Susto e Assombração. A partir do chamado da professora autora do documentário, retornamos ao CMET no segundo semestre de 2011, para uma nova experimentação, realizar um projeto fílmico que pudesse agenciar duas frentes de trabalho iniciadas por ela: a criação de um conjunto de personagens e cenários com papel e arame construídos com os alunos e um conjunto de contações de histórias, por parte dos alunos, relacionadas à sustos ou assombrações que se conservam em suas lembranças de infância. Assim, juntas, professora e pesquisadora lançam-se a uma experimentação com cinema, desconhecida, imprevisível, acionando uma máquina de guerra sobre si, sobre um coletivo de alunos, sobre o CMET, fazendo mudar os corpos. A máquina de guerra constitui um outro modo do existir que cresce molecular. É nômade, porque ela não fabrica pontos fixos, apenas velocidades. Diz-se que ela é de uma outra espécie e sempre exterior à soberania do aparelho de Estado que sustenda a visagem dominante do homem, já que sua existência foge e faz fugir da captura que se dá nos processos de subjetivação.

Histórias de Susto e Assombração surge, então, a partir das contações de histórias de assombração, fecundadas pela leitura do texto O Tesouro de Itapuã. As contações orais transmutam-se em gravações videográficas dos alunos contando suas histórias e em encenações fílmicas, com cenários de papelão, personagens de arame, pano e papel, bonecos 
de brinquedo, objetos cênicos de biscuit, etc., que entram como coadjuvantes das histórias contadas e, por bricolagem, agenciam-se para a constituição da obra. Estas contações, com todos os alunos e professoras-pesquisadoras dispostos em roda dentro de uma sala de aula, tornam-se momentos potentes dos quais proliferam as derivas do trajeto.

Tratam-se de fragmentos de suas infâncias envolvendo as imagens-clichês de bruxas, fantasmas e lobisomens em situações de sustos e assombrações que, no decorrer do processo, acionam blocos de infância nos alunos e professoras-pesquisadoras. Nas Histórias de Susto e Assombração, correm fluxos de vibrações imperceptíveis dos devires não humanos. Devir não-humano não se instala na esfera da imaginação, devir corre pelas veias. Deleuze e Guattari (1997a) dão ênfase à suposição de Duvignaud em que determinados fenômenos anômicos, que escapam aos regramentos sociais, são dinamismos irredutíveis que traçam linhas de fuga. Os devires não-humanos do homem podem animar uma máquina de guerra contra os poderes da subjetivação e da significância acionada por esta potência estranha do afeto: "efetuação de uma potência de matiIha, que subleva e faz vacilar o eu" (DELEUZE; GUATTARI, 1997a, p. 21). O relato das histórias, ao provir de lembranças infantis, arrastam consigo blocos de infância que expressam a criança nos alunos-adultos e nas professoras-pesquisadoras, fazendo mudar seus corpos. $O$ corpo da obra Histórias de Susto e Assombração expressa um fazer cinema que embala a diferença. Com blocos de sensações, o filme se torna, ele próprio, um corpo no mundo que habita o presente, composto de uma estética do silício. Molecularmente, o filme possibilita criar um alisamento no espaço através das linhas de fuga capazes de fazer expressar minorias. As imagens-tempo contidas na montagem fílmica fazem os espectadores, dentre eles, os autores das histórias e as professores-pesquisadoras, tornarem-se momentaneamente videntes. Através das Histórias de Susto e Assombração, uma obra maior que o filme fixado em arquivo digital, assitimos à individuação dos corpos, num eterno retorno da diferença.

Assim, um aprender que é, em suma, um diferir permanente, escorre por este processo. Se aprender consiste no encontro de diferenças, é no exercício da diferença que se dá o aprender. Aprender não se reduz à aquisição de um saber como o crê a imagem dogmática do pensamento. Aprender tem a ver com alegria, tem a ver com esse aumento de potência que se instala no exercício da diferença. Dessa maneira, na cartografia dos trajetos e devires deste fazer cinema em uma educação de adultos, pode-se vislumbrar algumas potências do agenciamento cinema-silício-educação. Este fazer cinema, que se viabiliza e se dissemina por uma estética do silício, vira arma de guerra que visa arrebatar, afetar alegremente os corpos. "Os afectos atravessam o corpo como flechas, são armas de guerra. Velocidade de desterritorialização do afecto." (DELEUZE; GUATTARI, 1997b, p. 18). Este fazer cinema, evento encarnado nesta experimentacão por um coletivos de professores, alunos, pesquisadora, salas, TIs, etc., afeta alegremente tais corpos como uma precipitação ou uma fulguração que aumenta a velocidade de suas desterritorializações. São as forças de resistência do homem que se compõem com a força do silício e do cinema para a invenção da existência.

As realizações fílmicas criadas por este coletivo de professoras-pesquisadora-alunos, ao longo dos três anos em que se efetua esta cartografia, são experimentações e expressões cinematográficas viabilizadas pelas TIs. Por isso, 
uma estética do silício subsiste na composição de uma imagem, uma paisagem de mundo, que expressa um estado de coisas, com suas velocidades, suas ligas, seus elementos, pi$x e l$, código numérico, energia elétrica, corpo humano, etc., tornando a matéria expressiva. Assim, funções científicas, blocos de sensacões artísticas e conceitos filosóficos embaralham-se tecendo um arranjo inextrincável entre os planos da arte, da ciência e da filosofia, construindo o plano de imanência da pesquisa ${ }^{11}$. No plano de referência da ciência, torna-se função, por componentes como velocidade, imagem cinematográfica, píxel, código numérico, etc., que serve à educação através das TIs; no plano de composição da arte, cria-se na interlocução com o cinema como modo de expres- são e torna-se um bloco de sensações que anima blocos de infância fazendo mudar os corpos adultos; no plano de imanência da filosofia, torna-se conceito, expressando a imagem que o pensamento se dá ao pensar.

Acreditamos que a multiplicação das experimentações com um cinema viabilizado por um conjunto de TIs no território da educação formal, pode investir práticas singulares que reinventem uma estética do silício, sendo capazes de produzir novas expressões de mundo. Trata-se de promover uma ética-estética da existência, uma arte da existência, que trace um caminho singular cuja ação de um indivíduo, em suas mudanças processuais, crie um estilo próprio. Trata-se de fazer de uma vida uma obra portadora de certos valores estéticos (FOUCAULT, 1985).

\footnotetext{
${ }_{11}$ Plano de imanência, de referência e de composição, são expressões cunhadas por Deleuze e Guattari para tratar as três caóides, da filosofia, da ciência e da arte, respectivamente, como formas do pensamento. São três maneiras de recortar e tratar o caos, em cada uma delas opera-se com elementos distintos e irredutíveis: conceitos filosóficos, funções científicas e afectos e perceptos artísticos. A junção dos três planos é o cérebro, a sensação artística não é menos cérebro que o conceito filosófico ou que as proposições científicas. Por isso os conceitos, as sensações e as funções se tornam indecidíveis, do mesmo modo que a filosofia, a arte e a ciência, se tornam indiscerníveis, compartilhando uma mesma sombra (DELEUZE; GUATTARI, 1996).
} 


\section{Referências}

BERGSON, Henri. A Evolução Criadora. Tradução de Bento Prado Junior. São Paulo: Martins Fontes, 2005.

CORRÊA, Elenice. Parangolés Eletrônicos, Expressões Audiovisuais de uma Estética do Silício. 2008. 110 f. Dissertação (Mestrado em Comunicação) - Faculdade de Comunicação, Universidade do Vale do Rio dos Sinos, 2008, São Leopoldo, BR-RS.

CORRÊA, Elenice; FONSECA, Tania Mara Galli; PASSERINO, Liliana. Filme Surdo - outra maneira de mer?: uma prática docente, um vídeo digital e suas potências. RENOTE: Revista de Novas Tecnologias na Educação, Porto Alegre, v. 9, n. 3, p. 1-9, dez. 2011.

DELEUZE, Gilles. Conversações. Tradução de Peter Pál Pelbart. Rio de Janeiro: Ed. 34, 2000.

DELEUZE, Gilles. Deux régimes dé fous: 1975-1995. Paris: Les Éditions Minuit, 2003.

DELEUZE, Gilles. A Imagem-Tempo. Tradução de Eloisa Araújo Ribeiro. São Paulo: Brasiliense, 2005.

DELEUZE, Gilles; PARNET, Claire. Diálogos. Tradução de Eloisa Araújo Ribeiro. São Paulo: Ed. Escuta, 1998.

DELEUZE, Gilles; GUATTARI, Felix. O que é filosofia? Tradução de Bento Prado Jr. e Alberto Afonso Muñoz. Rio de Janeiro: Ed. 34, 1996.

DELEUZE, Gilles; GuATTARI, Felix. Mil Platôs: capitalismo e esquizofrenia. Tradução de Ana Lúcia de Oliveira e Lúcia Cláudia Leão. Rio de Janeiro: Ed. 34, 1995. V. 2.

DELEUZE, Gilles; GUATTARI, Felix. Mil Platôs: capitalismo e esquizofrenia. Tradução de Suely Rolnik. São Paulo: Ed. 34, 1997a. V. 4.

DELEUZE, Gilles; GUATTARI, Felix. Mil Platôs: capitalismo e esquizofrenia. Tradução de Peter Pál Pelbart e Janice Caiafa. São Paulo: Ed. 34, 1997b. V. 5.

ENDERLEIN, Rolf. Microeletrônica: uma introdução ao universo dos microchips, seu funcionamento, fabricação e aplicações. São Paulo: Edusp, 1994.

FOUCAULT, Michel. História da Sexualidade. Tradução de Maria Thereza da Costa Albuquerque. Rio de Janeiro: Ed. Graal, 1985. V. 3: O Cuidado de Si. 
GERBASE, Carlos. Cinema: primeiro filme: descobrindo, fazendo, pensando. Porto Alegre: Artes e ofícios, 2012.

GUATTARI, Félix. Caosmose: um novo paradigma estético. Tradução de Ana Lúcia de Oliveira e Lúcia Cláudia Leão. Rio de Janeiro: Ed. 34, 1992.

Hengels, Friedrich. A Origem da Família, da Propriedade Privada e do Estado. Tradução de H. Chaves. Portugal: Ed. Presença, 1976.

LEMINSKY, Paulo. La Vie en close. São Paulo: Brasiliense,1994.

ZOURABICHVILI, François. Deleuze e a Questão da Literaridade. Educação e Sociedade, Campinas, v. 26 , n. 93, p. 1309-1321, set./dez. 2005.

Elenice Mattos Corrêa: Universidade Federal do Rio Grande do Sul - Porto Alegre - RS - Brasil. Email: ninimc@ gmail.com

Tania Mara Galli Fonseca: Universidade Federal do Rio Grande do Sul - Porto Alegre - RS - Brasil. Email: tfonseca@via-rs.net 